\title{
An activities-based approach to network management:
}

\section{An explorative study}

\section{Kristina Manser}

HAN University of Applied Sciences, P.O. Box 5171, 6802 ED Arnhem, The Netherlands.

Kristina.Manser@han.nl

Bas Hillebrand (corresponding author)

Institute for Management Research, Radboud University, P.O. Box 9108, 6500 HK Nijmegen, The Netherlands. b.hillebrand@fm.ru.nl. Tel: +31 243611847; Fax +31 243611933

\section{Rosalinde Klein Woolthuis}

Faculty of Economics and Business Administration, VU University Amsterdam, De Boelelaan 1105, 1081 HV Amsterdam, The Netherlands. r.j.a.kleinwoolthuis@ @u.nl

\section{Gerrit Willem Ziggers}

Institute for Management Research, Radboud University, P.O. Box 9108, 6500 HK Nijmegen, The Netherlands.g.ziggers@fm.ru.nl

\section{Paul H. Driessen}

Institute for Management Research, Radboud University, P.O. Box 9108, 6500 HK Nijmegen, The Netherlands.p.driessen@fm.ru.nl

\section{Josée Bloemer}

Institute for Management Research, Radboud University, P.O. Box 9108, 6500 HK Nijmegen, The Netherlands. j.bloemer@fm.ru.nl

\section{(C) 2016 Elsevier}

\section{This version is a preprint of}

Manser, Kristina, Bas Hillebrand, Rosalinde Klein Woolthuis, Gerrit Willem Ziggers, Paul H. Driessen, and Josée Bloemer (Forthcoming). An Activities-Based Approach to Network Management: An Explorative Study, Industrial Marketing Management. http://dx.doi.org/10.1016/j.indmarman.2015.10.004 


\section{Biographical sketches}

Kristina Manser is a lecturer at the HAN University of Applied Sciences in Arnhem and Nijmegen, The Netherlands. She holds a Master degree and a $\mathrm{PhD}$ in Business Administration from Radboud University. Her main research interests include the management of networks, the role of stakeholders in innovation processes, and innovation management. She published in Technological Forecasting \& Social Change.

Bas Hillebrand is associate professor of Marketing at the Nijmegen School of Management, Institute for Management Research of the Radboud University, the Netherlands. He studied business administration at Tilburg University and holds a PhD from the University of Groningen. His research interests include innovation, co-creation, stakeholder marketing, and institutional theory. He published in Journal of the Academy of Marketing Science, Journal of Product Innovation Management, International Journal of Research in Marketing, Organization Studies, Industrial Marketing Management, Journal of Business Research, and IEEE Transactions on Engineering Management, among others.

Rosalinde Klein Woolthuis is associate professor at VU University Amsterdam and a senior scientist at TNO. She got her PhD from the University of Twente. Het research interests include innovation, networks, trust, sustainability and institutional theory. She has published in journals such as Organization Studies, Technovation, Journal of Cleaner Production, and Technological Forecasting \& Social Change.

Paul H. Driessen is assistant professor of Marketing at the Nijmegen School of Management, Institute for Management Research of the Radboud University, the Netherlands. He studied business administration at Tilburg University and holds a $\mathrm{PhD}$ from the Center for Economic Research at Tilburg University. His research interests include stakeholder marketing, product 
innovation management and corporate social responsibility. His work was published in Journal of the Academy of Marketing Science, Journal of Product Innovation Management, Journal of Business Research, IEEE Transactions on Engineering Management, Technological Forecasting \& Social Change, Service Industries Journal, and Managing Service Quality, among others.

Gerrit Willem Ziggers is assistant professor of Strategy at the Nijmegen School of Management, Institute for Management Research of the Radboud University, the Netherlands. He studied animal science and business administration at and holds a $\mathrm{PhD}$ from Wageningen University. His research interests include alliance management, innovation management, and dynamic capabilities. He has published in Journal of Management Studies, Industrial Marketing Management, Trends in Food Science \& Technology, International Journal of Production Economics, Total Quality Management and Business Excellence, Critical Reviews in Food and Nutrition Science, and British Food Journal.

Josée M.M. Bloemer is full professor of Business Administration, specialized in market analysis and relationship management, at the Institute of Management Research of the Radboud University, the Netherlands. Her research interests focus on the management of relationships of organizations with many customers and employees. She published, among others, in International Journal of Research in Marketing, Journal of Business Research, Journal of Economic Psychology, Journal of Service Research, Journal of Service Management, European Journal of Marketing, Service Industries Journal and International Journal of Human Resource Management. 


\section{Research highlights}

- There are three distinct modes of network management: basically coordinated, controloriented and reward-oriented

- Basically coordinated networks can only be managed in a limited way

- Reward- and control-oriented networks can be managed, but through very different mechanisms

- Network actors try to match the management mode to their prevailing mental model and the type of network 


\title{
An activities-based approach to network management: \\ An explorative study
}

\begin{abstract}
Over the last few decades, the industrial marketing literature and the business network literature have promoted a holistic approach to marketing and provided a framework for understanding interorganizational networks. However, our understanding of how interorganizational networks govern themselves when developing innovations is still limited. Most network management literature does not focus on the activities employed by network actors and/or does not recognize that there may be different modes of network management. This study explores how, why and in which combination network management activities are employed in a network and in doing so proposes a new conceptualization of network management. Using primary and secondary data pertaining to eleven innovation projects, this study reveals how network management consists of combinations of (rather than individual) management activities undertaken to manage a network. This study identifies three distinct modes of network management: basically coordinated, control-oriented and reward-oriented. Moreover, this study proposes that network actors try to match the management mode to their prevailing mental model as well as the type of network (e.g. in terms of project innovativeness).
\end{abstract}

\section{Keywords}

Activities-based approach, innovation, network management, taxonomy 


\section{Introduction}

Increasingly, developing an innovation (i.e., a new product, service or process) has become a task too ambitious for a single organization because the required resources tend to be distributed over multiple organizations (Dhanaraj \& Parkhe, 2006; 1989; Teece, 1992). A recent literature review shows that a diverse network is important for achieving successful innovations (AarikkaStenroos et al., 2014). Therefore, many organizations join forces in inter-organizational networks (from now on shortly referred to as networks). A network is defined as a set of two or more connected relationships between organizations (Anderson et al., 1994). The relationships are connected to each other in the sense that exchange in one relationship depends on exchange in the other relationship. Defining the boundaries of a network is difficult and arbitrary, because a network "extends without limits through connected relationships" (Anderson et al., 1994, p.4). In this study we focus on the part of the network that the actors consider relevant in the context of an innovation project (Anderson et al., 1994; Håkansson \& Snehota, 1989).

Within the network literature two broad streams can be distinguished. The first stream of literature focuses on networks as a type of coordination and an alternative to markets or hierarchies (Powell, 1990; Williamson, 1985). For example, transaction costs economics explains that exchanges take place either in markets, hierarchies or networks, depending on the transaction costs associated with each. While this approach can explain when and why networks are a superior governance mode, it cannot reveal how networks themselves are managed.

The latter is the topic of the second stream of literature and also subject of the current study. Network management refers to the shaping of relationships, understandings and processes within a network to bring about task completion (Järvensivu \& Möller, 2009; Tsoukas, 1994; Watson, 2006). Because networks are loosely coupled coalitions of organizations (Provan, 1983) 
that are likely to have different objectives and conflicting processes, managing networks is challenging (Davis \& Eisenhardt, 2011). This is especially the case when networks include different types of actors (e.g., suppliers, customers, knowledge institutes), as is the case in open innovation (Rampersad et al., 2010; West \& Bogers, 2014; Zeng et al., 2010). At the same time network management is important because it influences value creation and network success (Möller \& Svahn, 2003; Provan et al., 2007; Provan \& Milward, 1995; Ritter et al., 2004).

Much of the literature on network management focuses on the contracts used (Gulati, 1995; Osborn \& Baugh, 1990) or the position of the network leader (e.g., Dhanaraj \& Parkhe, 2006; Park, 1996; Provan \& Kenis, 2007; Thorgren et al., 2009). For example, Provan and Kenis (2007) distinguish participant-governed (network managed by the network actors), lead organization-governed (network managed by one organization), and network-administrativeorganization-governed (network managed by an administrative board that is not part of the network). Similarly, Park (1996) distinguishes bilateral and trilateral networks. While these aspects of a network are important conditions for the functioning of the network, these studies do not inform us on how the contracts or the network structure are enacted.

Other literature in the realm of network management focuses on network capabilities (Blomqvist \& Levy, 2006; Möller \& Halinen, 1999; Ritter, 1999; Ritter \& Gemünden, 2003; Walter et al., 2006). These capabilities tend to be operationalized in terms of the activities that are needed to manage networks. However, this line of research assumes that organizations either have or do not have a network capability and in doing so largely ignores the possibility that there may be different configurations of network capabilities, i.e. different modes of network management. 
Therefore our study focuses on activities employed by network actors in their attempt to manage the network, taking into account that there may be different configurations (modes) of network management. In doing so our study addresses the call for more research focusing on the “everyday processes of complex innovation” (Dougherty \& Dunne, 2011, p. 1221) and proposes a conceptualization of network management that allows for multiple modes of network management. More formally, our study explores how, why and in which combination network management activities are employed in a network in 11 innovation projects. Our results suggest that there are three modes of network management: one that only shows basic coordination, one that is control-oriented, and one that is reward oriented. In addition, this paper provides insight in the underlying rationale for this conceptualization.

In the following, we first discuss previous literature on network management and explain our choice for an activities-based approach to network management. Next, we review the literature to present an inventory of network management activities as a starting point for our empirical investigation and discuss the relevance for focusing on combinations of network management activities. We then describe our method and present the results. We conclude with a discussion of the results and our contributions to the academic literature, as well as limitations and recommendations for further research.

\section{Theoretical background}

Engaging in networks implies that organizations can get access to resources and activities that are traditionally considered to be outside the control of the organization but also that other network actors gain some control over the resources and activities of the organization (Håkansson \& Snehota, 1989). Network actors thus become interdependent. Factors such as the 
availability of alternatives for the required resources and activities, the size of previous investments, and the network positions (e.g., Easton, 1992; Provan et al., 2007; Williamson, 1985) may make one network actor more powerful than another. The power distribution within a network may be important for the way it is managed (Rampersad et al., 2010).

In addition to power distribution within a network, several researchers of interorganizational relationships have studied other aspects of network management. The Industrial Marketing and Purchasing (IMP) group (e.g., Anderson et al., 1994; Håkansson et al., 2009) has been especially instrumental in promoting a holistic approach to marketing and in providing a framework for understanding business networks. IMP-researchers argue that networks have three components: actors, resources, and activities. Actors constitute (groups of) individuals or organizations that control resources (physical, financial, and human assets) and perform activities (Håkansson, 1987). These activities refer to what is done by the actors to the resources: "resources are combined, developed, exchanged or created by use of other resources" (Håkansson, 1987, p. 15). This can be done through activities such as production, logistics, administration, delivery, and information handling (Håkansson et al., 2009).

Researchers inspired by or closely related to the IMP group (Blomqvist \& Levy, 2006; Möller \& Halinen, 1999; Ritter, 1999; Ritter \& Gemünden, 2003; Walter et al., 2006) have operationalized network competence in terms of activities, thus providing more insight in what network management entails and stressing the importance of a focus on activities that are needed to manage a network. For example, Walter et al. (2006) measure an organization's network competence with 19 items that reflect how the organization deals with the relationships it has with its network partners. Summing the scores provides an estimate of how good an organization is in managing its network relationships. In doing so, this stream of literature focuses on the 
organization (rather than the network) and implicitly assumes that there is one type of network management.

However, other literature suggests that there are different modes of network management, by distinguishing two bases for relationship management: trust and control. Originating from social exchange theory, network management can be based on trust and originating from transaction costs economics, network management can be based on control (usually in the form of contracts). The literature has witnessed a heated debate about whether trust and control exclude each other or complement each other. Empirical research offers ambiguous findings regarding the relationship between contracts and trust: while some studies find contracts to facilitate trust building (Luo, 2002; Poppo \& Zenger, 2002, Lin et al., 2012), others argue that trust can serve as a precondition for contracts (Larson 1992; Ring \& Van de Ven, 1994), or that contracts can have a negative influence on trust between partners (Dyer \& Singh, 1998; Malhotra \& Murnigham, 2002). The reason for these ambiguous findings may be that the constructs of trust and contracts are too complex and abstract to form a good basis for explaining how trust and contracts interact and what network management exactly entails (Klein Woolthuis et al., 2005).

We suggest that at least part of the ambiguity may be resolved by focusing not on the bases of relationships and structure of networks, but on the day-to-day activities employed by network actors because this may provide more insight in how actors enact these network structures, contracts and trust. In other words, the collaboration within a network takes shape in the day-to-day activities that are embedded in the structural, economic, and the social context (Holmlund \& Törnroos, 1997). We therefore set out to explore which network management activities network actors employ, in which combinations they do so and why. Such an activities- 
based approach aligns with research that depicts management as a set of activities (e.g., planning, organizing, leading, controlling) (Manser et al., 2015; Tsoukas, 1994; Watson, 2006) and with network literature that suggests that more attention should be given to the process of orchestrating the network (e.g., Dhanaraj \& Parkhe, 2006; Jones et al., 1997). Focusing on network management activities also has managerial importance: if scholarship's ultimate goal is to inform action and provide managerial guidance, we need new models of network management that fit this need (McGuire, 2002). Only if we develop a more detailed insight into network management activities we can begin to understand "what exactly should be done and how" (Provan \& Kenis, 2007, p. 248).

\section{Network management activities}

A review of the literature on networks, inter-organizational relationships, and alliances provides a set of network management activities which we use as a starting point for our research.

Communicating is defined as informing, talking and negotiating with each other. It ensures that network actors know all the relevant issues regarding the network and has been found an important mechanism (Grandori \& Soda, 1995; Walter et al., 2006). Planning is defined as setting performance standards and objectives. Planning may help effective management of the network and allows for evaluation of the output (Das \& Teng, 2001; Grandori \& Soda, 1995; Järvensivu \& Möller, 2009; Ritter, 1999; Ritter et al., 2002). Monitoring has also been noted as a management activity in the literature (Das \& Teng, 2001; Kenis \& Provan, 2006; Ritter et al., 2002). It refers to the close observation of the process, outcome and behaviours of network actors to evaluate the results according to predefined performance standards and network objectives. Monitoring is considered to stimulate network actors to 
conform to the rules and produce the desired output (Das \& Teng, 2001; Kenis \& Provan, 2006). Sanctioning is defined as the efforts of an authorized actor (e.g., the project leader) to punish network actors. Sanctioning may reduce opportunistic behaviour in the network because it shows actors that sanctions will be implemented if they do not act according to the rules (Avadikyan et al., 2001; Tenbrunsel \& Messick, 1999). Using social control refers to collectively pressuring network actors to adhere to network norms, values or goals (Jones et al., 1997; Ouchi, 1979). It thus defines and reinforces the parameters of acceptable behaviour by demonstrating what can happen if norms and values are violated. Finally, rewarding is defined as using an incentive scheme to stimulate network actors to defined objectives (Grandori \& Soda, 1995; Gulati \& Singh, 1998). Although rewards steer behaviour, they do not control it in the sense of 'safeguarding for opportunism' (Williamson, 1985). Rewarding mainly steers towards positive and extra-role behaviour (Van Dyne \& LePine, 1998).

Thus, several studies have identified activities to manage networks. However, these studies typically investigate (a limited number of) activities independently from each other (Capaldo, 2014). Yet, network management activities are likely to complement, substitute or exclude each other (Klein Woolthuis et al., 2005). As a result they are likely to appear in specific combinations or modes, each characterised by the presence or absence of specific activities. By focusing on combinations of network management activities, this study addresses potential synergy and/or trade-offs between activities and provides a better understanding of how networks are managed. The resulting activities-based taxonomy of network management can provide guidelines for further research, as well as a repertoire of possible solutions that network actors may use to deal with the complex challenge of managing networks (Grandori, 1997). 


\section{Method}

Because this study aims to explore how, why and in which combination network management activities are employed in a network, a case study approach seems warranted (Yin, 1994). In this section we discuss how we selected our cases, how we collected our data from these cases, and how we analyzed the data.

\subsection{Research design}

We followed the epistemological tradition of comparative case studies as described by Yin (1994). We employed a multiple case study design with 11 cases, each case representing an innovation project realized within a network of organizations. We selected the cases based on two criteria. First, we selected sustainable (i.e., environmental friendly) innovation projects, because these tend to be very complex and require input from various parties (Dougherty \& Dunne, 2011), making network management a relevant issue. Second, to make sure that we could gain a good overview of the whole innovation project and to enable respondents to recall what had happened in their network, we selected projects that were either recently completed or close to completion.

To obtain variation across cases (allowing us to capture a diverse set of contexts and thus more possibilities to contrast cases and generalize results), we furthermore selected projects to differ on two criteria. First, we selected projects aimed at developing product innovations (e.g., the Electric Car case), as well as projects aimed at developing process innovations (e.g., the Food Chain case). Appendix A includes a short description of each case. Second, based on secondary data and initial communication with contact persons we selected both successful and unsuccessful projects. Success was defined as a preliminary (a priori) assessment of the overall, 
technical and commercial performance of a project. Table 1 shows how each case scores on project success.

$$
==\text { Insert Table } 1 \text { about here }==
$$

As shown in table 1, four projects were of an on-going nature, whereas seven projects had a predetermined deadline. Network size varied from 3 to 29 participants, although most networks were small (less than 10 participants). We also established the innovativeness of each project because extant innovation literature suggests that the way the network is structured and managed may relate to the innovativeness of the project (Möller \& Svahn, 2006; Rindfleisch \& Moorman, 2001). Project innovativeness (in terms of involving new technologies as perceived by the respondents) ranged from low (in 2 cases) to medium (5 cases) to high (in 4 cases).

Projects also varied in terms of contract completeness, defined as the number and specificity of contractual clauses (on matters such as financial obligations, licensing, rules, and deadlines) (Poppo \& Zenger, 2002). Contract completeness ranged from very general and unspecified (as in the case of Food chain) to very detailed and customized to the specific situation, covering many aspects of the cooperation and future contingencies (as in the case of C2C Building). Trust, defined as the respondents' overall assessment of the degree to which network actors have confidence in each other's competences and good intentions, ranged from low ( 1 case) to medium (6 cases) to high (4 cases). In eight cases dependence was relatively symmetric, whereas in the remaining three cases some network actors were clearly more dependent on other network actors than vice versa. Dependence is here defined as the degree to which there was balance in the network with regard to the importance of the project and the 
project actors (i.e. whether the resources brought in by the actors were considered unique), as perceived by the respondents. In short, the cases are relatively diverse in nature.

\subsection{Data collection}

To gain background knowledge of the cases and triangulate the findings (Jick, 1979), we first collected secondary data (business reports, project plans, newspaper articles, website information etc), producing more than 1200 pages of text pertaining to the background of the projects, participating actors, project performance and the projects' evolution over time.

We then interviewed members of the networks, whom we identified through the secondary data. We began by interviewing the main actor in the network, usually from the organization that initiated the project. Using a snowballing technique, additional selection of respondents was based on their involvement in the network and the diversity of perspectives on the network. In total, we interviewed 42 respondents in 47 interviews (some respondents were interviewed twice). For all cases we interviewed the project leader and at least one person from another organization. As most cases were relatively small in terms of number of participants, we obtained a good insight in the projects with a relatively small number of interviews per case. Detailed information on the collected data can be found in Table 2 .

$$
==\text { Insert Table } 2 \text { about here }==
$$

The semi-structured interviews were guided by a topic list (see Appendix B for an abridged version), providing a general guideline for the interviews. Follow-up questions depended largely on the answers provided by the respondents. More specifically, whenever the respondents 
mentioned a network management activity, we asked follow-up questions to obtain a better understanding of its application, such as why it had been done (or not) and if it might complement or influence other activities. Thus, we gained an understanding of when and why network management activities were employed in combination.

Interviews started with some general background questions about the product (e.g., in terms of functionality and newness), the network (e.g., origin, project goal), and the participants (e.g., roles). To determine how the network was managed, we then used three different interviewing techniques to increase the probability of gaining a comprehensive overview of the network management activities and management modes.

First, we applied a critical incident technique (Flanagan, 1954). We asked respondents to recall a particular memorable incident (positive or negative) during the project and then asked them to describe when this had happened, what had happened, who were involved, what the circumstances were of the incident, and how the network dealt with those incidents. Because many incidents related to network management issues, the resulting narrative provided in a rich account of how each network was managed without having to prompt the respondent with network management-related concepts. To obtain an in-depth understanding of the working of the activities we also asked why actors had acted in a particular way.

The second technique consisted of open questions about network management. For example, we asked respondents to explain how the network actors knew what they had to do and how the network ensured that every actor fulfilled its role. We encouraged respondents to give concrete examples of when, how and to what effect these activities were employed, thus obtaining a rich understanding of the activities. Respondents were not directed in their answers, resulting in a relatively unbiased view of what the respondents believed were important activities 
for managing the network. Again, follow-up questions were asked to obtain a better understanding of why specific activities had been employed or not.

Third, to check if activities not yet mentioned in the interview (but identified in the literature study) were relevant for that network, we asked directly whether a specific network management activity had been used. For example, when the respondent had not yet mentioned rewarding, we asked to what degree incentives and rewards were used to manage the network. Follow-up questions prompted the respondent to describe what kind of rewards were used, who rewarded, why (or why not) rewards were used, when rewards were given et cetera.

\subsection{Data analysis}

Interviews were tape recorded and fully transcribed. In those instances where tape recording was not possible, detailed notes were made during the interview and extended reports of the interviews were made right after the interview. Transcribed interviews were entered into a qualitative data analysis program (Atlas.ti) and coded manually following a hierarchical coding scheme. For example, 'communicating' was coded according to the means of communication (telephone communication, email communication, and face to face communication) and the aim of communication (to stimulate, to inform, and to coordinate). The coding scheme combined descriptive, interpretive and pattern coding (Miles \& Huberman, 1994). The initial codes were based on the activities found in the literature and additional codes and refinements of the initial codes were spurred by the case data. We also developed comments and memos (Miles \& Huberman, 1994), most of which were tied to a specific code and offered a construct definition, often together with a text segment that illustrated the code. Other memos stated norms for coding or summarised essential aspects of a case. 
Based on our data, we made a qualitative assessment of the extent to which each activity had been employed in each case, from absent through low through medium to high. The coding and analysis procedure was iterative. After we assigned codes and achieved the initial analyses, the three lead investigators (and in a later stage the whole research team) discussed the results and further possibilities for analysis. We stopped the iterative process when we arrived at a taxonomy with classes that were both exhaustive and mutually exclusive (Bailey, 1994) and when the taxonomy could be backed up by a reasoning supported by empirical findings from the cases and/or theory. More specifically, based on our assessment of the extent to which activities had been employed, we made tables (similar to table 3) to analyze whether and how activities were related, i.e., in which combinations the activities appeared and whether we could find any patterns. In addition, and importantly, we investigated the data to find underlying reasons why actors employed the activities in combination or why they refrained from using specific combinations of activities, thus providing more confidence in the resulting taxonomy.

\section{Results}

The data reveal a wide range of network management activities. Two activities identified in the literature (planning and monitoring) were also identified in our cases. We also found that communicating needed to be refined because it may have two purposes: communicating for coordination (the extent to which network actors inform, talk and negotiate with one another to ensure that activities are aligned) and communicating for stimulation (the extent to which network actors interact with each other to ensure they are motivated to do their utmost to make the project succeed). Based on the data, we also decided to refine sanctioning because it may be used both formally (based on explicit agreements defined in a contract) and informally (based on 
unwritten rules). Hence, sanctioning formal refers to threatening to punish network actors (e.g., reduce their resources, or start legal procedures) for not meeting written agreements, while sanctioning informal refers to making similar threats for not meeting unwritten, mutually agreed upon agreements, without the ability to fall back on a formal contract. Similarly, rewarding has a formal and informal form. Rewarding formal refers to giving pre-defined incentives for meeting objectives, while rewarding informal refers to showing appreciation for the achievements of network actors by giving spontaneous rewards (e.g., an unexpected bonus or a party) for which there is no formal obligation. In addition, the analyses reveal that social control can be used before or after a specific incident; using ex post social control refers to creating social pressure on project participants who violated project goals, norms or values to reinforce the parameters of acceptable behaviour, whereas using ex ante social control refers to directing the behaviour of network actors by showing in advance what is desired (e.g., by reminding network participants to come to a meeting or meet a deadline). Social control differs from sanctioning informal in that it focuses on defining expectations of what is acceptable, whereas sanctioning informal involves a concrete threat of, for instance, removing an actor from the network or withholding resources.

We identified one activity in our empirical study that was not identified in the literature review: encouraging a solidarity atmosphere, referring to explicit attempts to make network actors feel a valued part of the network and trying to create a friend-like group of people

\subsection{An activities-based approach to network management}

Further analyses show that the network management activities occur in specific combinations that constitute three modes of network management (see Table 3). Basically coordinated networks do not employ any network management activities beyond the basic ones that are 
employed in all cases: planning, monitoring, and communicating for coordination. The other two modes go beyond these basic activities but in different ways. Control-oriented networks combine basic activities with control activities that are aimed at reducing opportunism, namely using social control and sanctioning. Reward-oriented networks use basic activities together with reward activities that aim to motivate network actors by communicating for stimulation, rewarding, and encouraging a solidarity atmosphere. This taxonomy resembles the markethierarchy-network division from Transaction Cost Economics (Williamson, 1985), providing additional confidence in our findings. The distribution of the cases over the three modes is relatively even; we found three cases to be basically coordinated networks and four cases to belong to each of the other two network management modes.

$$
==\text { Insert Table } 3 \text { about here }==
$$

\section{Mode 1: Basically coordinated network}

The Bus, Food Chain, and Breathing Window cases are basically coordinated networks that rely on a combination of communicating for coordination, planning and monitoring, but no other network management activities. This combination seems necessary for a minimum degree of network management; all networks use them and some respondents explicitly argued that these activities were essential to network management. For example, one respondent explained:

Each time we met, a plan was made. It is very important that we know what we have to do. (Project monitor, Food Chain)

Similarly, monitoring was considered very important. Respondents noted that they monitored budgets, outcomes, and activities to ensure that everyone was doing whatever had been agreed 
upon and to adapt when necessary. The project leader of the Bus case stressed that "the progress of the project is constantly monitored" and that they even hired external help for that because "that makes the measurement very objective". Communicating for coordination purposes was also considered essential to keep all network actors up to date and to negotiate and arrange next steps. For example, in the Bus network participants met six times per year, with the main actors even meeting several times a week to coordinate their highly interrelated tasks. Similarly, the network actors in the Breathing Window case met on a weekly basis to discuss progress and what changes had to be made to the planning.

At the same time, basically coordinated networks did not use control and reward activities. This is partially due to the asymmetric dependence in these networks (see Table 2), hampering the use of control and reward activities. For example, in the Bus network the project initiator had no alternative partners. The dominant parties were unwilling to sign contracts that included sanctioning because that would limit their freedom. In absence of dependence, the possibility to employ control activities was limited. Similarly, in the Breathing Window case, one actor deliberately tried to remain independent:

We just try to be completely independent from firm A. (...) We do not need anything from them or vice versa. So trust is not an issue here. (Network actor, Breathing Window) Likewise, rewarding was not considered a real option because that would have required relationships that go beyond pure transactions. However, in these cases actors showed little affective commitment to each other or to the project. As one actor sighed, everyone "just went their own way".

Due to the lack of dependence and affective commitment to each other or the project, few activities seemed effective, or as the project leader of the Food Chain case lamented, "This 
project just cannot be managed." (Project leader, Food Chain). In such situations network actors had to rely on basic activities only.

\section{Mode 2: Control-oriented network}

Four cases (Greenhouse, Packaging, Printer, and C2C Building) add a combination of control activities (social control and sanctioning) to the basic activities, but refrain from using reward activities. These networks show a strong focus on control and prevention of opportunistic behaviour, prompting us to call them control-oriented networks.

The data show that sanctioning plays a particularly important role by allowing network actors to keep control over the network and reduce opportunism, whether formally or informally. For example, the project leader of the Printer case stressed they considered it important to have agreements and warnings laid down in writing because this makes it possible to use them later as legal documents, in case conflicts would escalate and the case would be taken to court:

Everything we communicated, we always had it checked by our lawyer. I would write the outline and the lawyer would check the legal aspects. (Project leader, Printer)

Similarly, in the Packaging case, it was considered important to safeguard intellectual property: We have signed a non-disclosure agreement with all parties and all rights are going exclusively to the initiating party. This has been very important lately; we have already made use of it once in order to protect our ideas. (Network actor, Packaging)

Inspection of the contracts that are used in the Packaging network confirms that they are quite extensive and that they list especially the sanctioning elements and the protection of intellectual property. 
Control-oriented networks also employed informal sanctioning, i.e. sanctioning a breach of an implicit understanding of agreements. Moreover, our data show that it is the threatening with the possibility of sanctioning rather than the actual sanctioning that was considered important. For example, in the Greenhouse case all network actors were well aware of the fact that there could be sanctions when informal agreements were not met. As the project monitor noted:

It was not formal, but you could be kicked out of the network. (Project monitor, Greenhouse)

Control-oriented networks are also characterised by a heavy reliance on social control. Unlike sanctioning, social control does not involve punishment, but instead uses social pressure to correct the behaviours of network actors after a violation to make sure the unwanted behaviour will not occur again. For example, network actors in the $\mathrm{C} 2 \mathrm{C}$ Building case were used to "set things straight informally", as one of the network actors called it: whenever one of the actors was not living up to expectations, a call would be made to make sure the actor knew his behaviour was not acceptable. Social control can also be used to direct behaviour of network actors in advance, to prevent unwanted behaviour. For example, the Packaging network recorded the performance of individual network actors and communicated the information during network meetings with the explicit objective of publicly revealing who had done their jobs and who had not. As the project leader explained, poor performance makes an individual member feel pressured to do better next time:

Everybody else can see this and this pushes them [to do better]. (Project leader, Packaging) 
Similarly, in the Greenhouse case the project leader used to call network participants before a meeting to tell them that they were expected to come. By calling and making expectations explicit, social pressure was created.

The networks employing a control-oriented management mode did not use reward activities. Our data suggest that the beliefs held by network actors with regard to managing networks may be an important reason. For example, when asked whether they used reward activities, the project leader in the packaging case responded:

No, no, we are not good at rewarding, we don't celebrate things. (Project leader, Packaging)

Similarly, the project leader of the Printer case recalled:

We did not praise each other or have a fun and amicable atmosphere. That's not in our character. That is not to say that we were not friendly: we always stayed polite. (Project leader, Printer)

Please note that respondents consider themselves to be not good at using reward activities or in conflict with their character. In other words, rewarding is not part of their repertoire when in a business relationship. In the $\mathrm{C} 2 \mathrm{C}$ Building case a network actor noted that "it is not in our culture" to reward and praise each other or to deliberately create an atmosphere of solidarity, suggesting that this way of network management was foreign to the mental model shared in their culture.

Network actors in the control-oriented cases consider control activities a better way of managing in complex network situations. They recognize that, although actors may have a common goal in the project, they also have individual interests that will prevail over shared ones. 
They consider control activities as a way to create a transparent situation with little room for opportunism or distrust to arise. For example, a respondent from the $\mathrm{C} 2 \mathrm{C}$ Building case noted:

We split up task execution and monitoring of these tasks. This is how we keep each other on our toes, and we never get surprises. This prevents distrust to arise. (Network actor, C2C Building)

In other words, the use of control activities while refraining from reward mechanisms seems to be ingrained in the prevailing mental model of the network actors and hence also in their way of doing business.

\section{Mode 3: Reward-oriented network}

Four cases apply, in addition to the basic activities, a combination of reward activities: the Electric Car, the Hen Housing, the Bulb Drying System, and the Organic Rankine network. Control activities are largely absent though. This reward-oriented mode is characterised by a strong focus on rewarding network actors for doing a good job, motivating them and creating an atmosphere of solidarity.

Reward-oriented networks indicate high levels of communicating for stimulation. Communication is frequent, in some cases daily, and is not just used to coordinate tasks, but also to constantly remind network actors how important they are for the project and the importance of its ultimate goal. Our respondents stressed that the positive and stimulating way of communicating was paramount. For example, one project leader explained:

We share information [and in doing so] we are critical in a positive rather than a negative way. The attitude at that moment is a positive feeling: we're going for it, we're going to make a beautiful project out of it. (Project leader, Bulb Drying System) 
Especially stressing the joint goal is frequently mentioned as a good way to stimulate network actors. For example, the project leader of the Hen Housing network explained:

I regularly show the business plan to the whole group. I think this is a good way to show them what we are doing together, to create a positive drive and stimulate them, something like: 'this is what we are doing together'. (Project leader, Hen Housing)

Our data also suggest that stimulating communication tends to include a recognition of each other's work: respondents from the reward-oriented cases indicated that in their projects actors tried to stimulate each other by telling each other that the work they do is valuable and recognised. A respondent from the Electric Car network elaborates on this point by stating that any human wants to be valued and that it is important to respond to that need:

If everybody is doing overtime on Sunday [...], then you have to value that, really value that. You should tell them that you appreciate it and that it is well done. This also works for me: if I work hard on Sunday and somebody tells me 'Tim, you did a great job', then I think 'thank you for noticing that I worked hard and for giving me a compliment'. We like to be appreciated and to be valued. (Project leader, Electric Car)

Reward-oriented networks also emphasise the use of formal and informal rewarding. Several respondents indicated that formal rewards, such as contracted bonuses when project objectives are met or exceeded, were frequently used and motivated them to meet set objectives for extra remuneration included in the contracts. For example, a network actor in the Electric Car case stated:

We will get bonuses when we have produced 300 electric cars and that is a very big bonus. Everybody finds that very interesting. (Network actor, Electric Car) 
Similarly, a farmer from the Hen Housing network revealed that he would "score better" if the project succeeded:

The better the hen housing system works, the more money I can earn. (Network actor, Hen Housing)

Informal rewarding was also used. For example, network participants of the Electric Car case were spontaneously invited on a city trip with their families when they reached a milestone and similar activities with families and friends were central to the collaboration in the Organic Rankine case.

The data show that all four reward-oriented networks in our study are characterised by encouraging an atmosphere of solidarity. Exchanging social information and making such exchange possible was considered an important instrument for achieving more solidarity. For example, the project leader of the Electric Car case stressed the importance of social information: I like to have them all around a table, with food, so that we can eat together. Then you also get to hear about problems in the family or about the illness of a project partner's wife [...] that is important as well. That is their life and it is mine, as well. In that way we are able to create a special team spirit. (Project leader, Electric Car)

In this project, the offices (which all participating organizations use freely) were designed to stimulate spontaneous exchanges and to give network actors the sense that everyone was part of the project. A network actor thus shared his experiences:

It is important that you are not working in hierarchical levels. I was sitting next to the project leader and the secretary in the office. This supports the exchange and the stimulating atmosphere. This is good for the project. (Network actor, Electric Car) 
In a similar vein, the project leader of the Organic Rankine case stressed the importance of being a circle of friends, without distinction of one being a professor and the other a 'simple' mechanic:

We have been crawling through these machines together, with the welders... This makes that there is a joint feeling. (Project leader, Organic Rankine)

While the reward-oriented cases show high levels of using reward activities, they hardly use control activities. Again, our data suggest that this is due to the beliefs network actors hold with regard to dealing with each other in complex innovation projects. Network actors in the rewardoriented networks showed a clear personal preference for rewarding rather than controlling. For example, the project leader of the Electric Car project expressed:

I do not see much in sanctioning, I prefer motivating people. [...] Control and innovation are two things that do not go very well together. (Project leader, Electric Car)

Similarly, the project leader of the Bulb Drying System network observed:

We try to focus on the solutions [...]To be solution-focused works much better than working with penalties. You do not solve problems with penalties. (Project leader, Bulb Drying System)

The preference for rewarding over controlling in these cases seems to be a strongly held belief about managing networks. For example, when asked to describe why his project was managed more by rewarding than by controlling, one of the respondents for the Organic Rankine case responded:

It is one's character [...] it is sort of a philosophy. (Network actor, Organic Rankine) As a result, cooperation with other actors is not always easy as not all organizations hold the same beliefs. This was experienced in the Organic Rankine project: 
We had major differences with [another actor from the construction industry]. They have a completely different frame of mind. [...] We addressed this with them and told them this mentality would not work in this situation. Their mentality goes back to the dominant culture in the construction industry and that led to some clashes. (Network actor, Organic Rankine)

To prevent such clashes from happening, in all reward-oriented cases partner selection focused not only on whether or not the potential partner had the capabilities to fulfil its task, but also on whether the potential partner had the intrinsic motivation to make the project a success. Our respondents showed great awareness for the importance of selecting partners that fit the project team and that have the same ideas about how the project should be managed. As one network actor stated:

You have to have the right people for this sort of work and interaction [...] attract people that have the same attitude. (Network actor, Organic Rankine)

Respondents argue that this creates trust within the project team and consciously use management activities that stimulate positive behaviour, rather than controlling potential negative behaviour. Actors within the reward mode seem to believe that intrinsic motivation and empowerment (and lack of control) are the best way to govern innovative projects, as this makes actors achieve the most. As one of the respondents phrased it:

There is trust that partners have an intrinsic motivation to achieve set goals together. [...]. We all have the same drive and that is to make this a success, and if you all want that, we can achieve a lot. Well, that's how I feel it. (Network actor, Hen Housing) 
Like in the control-oriented network, the preference for this specific management mode seems ingrained in the mental model of the network actors: actors believe that goals are better achieved by empowering and stimulating people than through control activities.

\subsection{Network characteristics and management modes}

While we observed that the choice for either control- or reward-oriented management modes is predominantly determined by the mental model network actors adhere to, other network characteristics also seem to play a role. One of the most striking network characteristics is the innovativeness of the project. The networks engaged in more innovative projects used a rewardoriented management mode. Projects in the control-oriented networks were less innovative (see table 1), making it easier to define tasks and expectations and execute tasks individually according to the agreement. Consider for example the $\mathrm{C} 2 \mathrm{C}$ Building case:

Work is agreed on formally and formalized in normal contracts. In the execution of the project we all have our own role. (Network actor, $\mathrm{C} 2 \mathrm{C}$ building)

In contrast, reward-oriented networks were very innovative and characterized by high uncertainty. As a result, network actors could not specify the contract in great detail and goals and plans changed continuously. For example, the leader of the Organic Rankine project noted:

We did have a business plan, but [..] this was very uncertain. You sail more on an overall vision. [...] you want a solution, but you do not know exactly what you are asking for. (Project leader, Organic Rankine)

As a result, actors in these networks were expected to be actively involved in joint problem solving and to do more than specified in the agreement: 
You need people that can take their own responsibility, that have the willingness to fundamentally think in terms of solutions, and that are willing to think along with you. (Network actor, Organic Rankine)

Actors that were unlikely to contribute to the joint problem solving in uncertain innovative projects were excluded from the project in the selection process. For example, in the Bulb Drying System case certain potential partners were not selected for the project because:

They were not moving fast enough, they weren't inventive enough. [It is] really on the basis of whether one can solve a problem. (Network actor, Bulb Drying System)

Thus, network actors with less innovative projects tend to opt for a control-oriented mode and network actors with highly innovative projects prefer a reward-oriented mode. In some cases respondents suggested that they might have used another management mode if the project would have been more or less innovative. The Organic Rankine case is especially interesting in this respect as this project was moving out of the $R \& D$ phase:

As we moved closer to the realization and manufacturing phase, we had to start operating according to stricter practices. When we started to sell the first machines, we switched to a completely different management style. (Project leader, Organic Rankine)

This illustrates that network actors feel that the management style might have to be altered when moving from an uncertain pioneering phase to a less innovative manufacturing and market introduction phase. It is interesting to note that the project leader cited above believed himself to be unable to take make that switch:

We then also hired a new manager, that took over the daily management from us. He was a former project manager in the construction industry. [...] I was very happy that he did 
things differently. That approach is not in my character. (Project leader, Organic Rankine)

This again illustrates the earlier noted importance of the prevailing mental model held within the network and that such models may not be easy to change.

Apart from project innovativeness, we found two other factors to be related to the choice for a certain network management mode: the interpretation of the role of both trust and dependence. In both the control-oriented and the reward-oriented networks the level of trust was medium to high (see table 1), but the degree to which network actors relied on trust differed. In the control-oriented networks actors indicated that they did not rely on trust as they considered it to be fickle and unreliable, and hence rendered reliance on trust to be naive. For example, in the Packaging case it is noted that:

Trust can end very quickly. [...] In our industry it is hard business and in the end it is important to earn money and then you need to rely on businesslike agreements. (Project leader, Packaging)

Similarly, in the C2C Building case, one respondent argued:

Trust is good and quick, but [should be used] with caution: trust should not become naive. (Network actor, C2C Building)

Because of this cautious interpretation of the merits of trust in controlling for opportunism, actors seem more prone to use the control-oriented mode. In contrast, in the reward-oriented mode trust was considered to be the fundament for the collaboration:

Blind trust in one another [...] That has really been the basis for success. (Network actor, Organic Rankine) 
The difference between control-oriented networks and reward-oriented networks in terms of their reliance on trust may be partially explained by the different manner of selecting partners (see table 1). While in both modes partners are selected based on their capabilities, reward-oriented networks also select on the basis of intrinsic motivation: the will of all actors to make the project a success and the fun and satisfaction that these partners get from achieving this. Having secured such motivated fellow network actors, actors belief that everyone will voluntarily refrain from opportunism and do their utmost to achieve joint goals. As a result, network actors feel less inclined to use control mode activities:

I think that trust was in general high. I think that is the reason why there was little emphasis on formal written agreements. Yes, I think that there was quite a lot of trust. (Project monitor, Hen Housing)

Similarly, although dependence was symmetric in both the control-oriented networks and reward-oriented networks, also dependence was interpreted differently. In the control-oriented networks, dependence was often referred to as a negative fact-of-life that one has to deal with. One of our respondents formulated this notion as:

We cannot escape from each other. (Network actor, Printer)

In the reward-oriented networks, dependence was seen as a voluntary commitment to each other and to the joint project. Moreover, dependence was even considered a precondition for success:

You commit yourself. Voluntary dependence is necessary to make a project a success. (Network actor, Bulb Drying System)

Thus, although dependence seemed the same, the interpretations varied from 'no escape', with a preference for the control mode, to 'voluntary dependence', with a preference for the reward mode. 
Interestingly, we observed that contract completeness in reward-oriented networks was not necessarily lower than in control-oriented networks. This might be related to the above mentioned interpretation of dependence: actors in reward-oriented networks may voluntarily commit to the network and formalize this commitment in the contract, whereas actors in controloriented networks specify contracts to safeguard their interests. The resulting contract completeness may thus be the same but have very different interpretations.

\section{Discussion}

This study suggests that, when conceptualized in terms of activities, network management takes the form of either very basic coordination, or control-oriented management, or reward-oriented management. Moreover, this study shows combining these modes of network management is highly unlikely because they are based on incompatible mental models or circumstances.

Our results show that network management beyond basic coordination requires a certain level of (mutual) dependence and commitment. What makes the basically coordinated mode unique is that in this mode no reward or control activities are employed: actors do not see viable possibilities to manage the network beyond a very basic level. This finding is supported by earlier studies that found that in asymmetric relationships coordination may be difficult to achieve (Rampersad et al., 2010): actors are not willing to commit themselves (e.g., through contracts), trust is hard to establish and conflicts are more likely to occur (Kumar et al., 1998). Under such circumstances, relationships are hard to manage. Our study thus confirms the importance of dependence for a good understanding of network management.

Our identification of the basically coordinated mode as one of the three network management modes is interesting because it contributes to the debate about whether networks 
can be managed (Rampersad et al., 2010; Ritter et al., 2004). Some authors argue that networks are emergent and cannot be managed (Podolny \& Page, 1998; Powell, 1990), while others posit that they can be managed (Heikkinen et al., 2007; Provan \& Kenis, 2007). Our study suggests it depends on the network: basically coordinated networks can only be managed in a limited way, but reward- and control-oriented networks can be managed, although through very different mechanisms.

The other two network management modes seem to be based on the actors' mental models about managing networks effectively. For example, network actors in reward-oriented networks describe their network partners as people that have intrinsic motivation, exercise selfcontrol, are creative and ingenious in solving problems, and have joint goals. Commitment is crucial in this mental model. By stimulating affective commitment, e.g. through informal contact and social events that led to friend-like relationships, extra-role behaviour is encouraged (Sahin, 2012; Van Dyne \& LePine, 1998), which is reflected in the cases as a mentality to 'think along' and come up with solutions that could not specified beforehand. Strikingly, our data show that the network actors' prevailing mental model about network management seems to be part of who they are ("it's in our nature"), suggesting that these mental models are deeply rooted within the beliefs of these actors. In that sense, these mental models seem very similar to the dominant logics Prahalad and Bettis (1986) proposed as guiding schemas, or shared cognitive maps, that management teams have learned over time to draw on when making decisions and that are difficult to unlearn. Also, these mental models resemble theory $\mathrm{X}$ and theory $\mathrm{Y}$ (McGregor, 1960), referring to two distinct sets of assumptions that managers hold with regard to their employees (McGregor, 1960; Sager, 2008). In line with literature on theory X/Y and dominant logics, our findings suggest that mental models may serve as an underlying rationale for why 
actors use a particular management mode while refraining from another. Mixing management activities from different management modes may be "highly problematic" (Truss et al., 1997, p. 55) because each rests on a different set of assumptions on human nature and managerial control strategies. In other words, activities within one management mode belong together because they share common underlying assumptions. While we cannot exclude the possibility that a fourth mode that combines control and reward activities exists, our theorizing about mental models may explain why we did not find such a fourth mode: the underlying assumptions for each set of mechanisms are difficult to reconcile.

While actors in a particular network may adhere to different mental models (as in the case of Organic Rankine), in most cases we observed that they use similar mental models. We offer two explanations for this finding. First, network actors may share the same mental model because they have had similar experiences that led to this mental model (Prahalad \& Bettis, 1986), e.g., because they are from the same industry. Second, our results suggest that partner selection based on intent criteria (Roy, 2012), such as intrinsic motivation, is crucial to create networks of like-minded actors. Selecting on intrinsic motivation may serve as a kind of proxy for sharing the same ideas about how innovation projects are to be governed and may explain why networks are relatively homogeneous in terms of mental models (Bridoux \& Stoelhorst, 2014).

While shared mental models may underlie the choice for a network management mode, this does not imply that other factors are irrelevant. Especially the innovativeness of the project may also steer network actors' choice of management mode: while network actors have a natural inclination towards one mode over the other, they also take into account the project's innovativeness. Actors realize that highly innovative projects may require a reward-oriented 
management mode, as there is too much uncertainty to apply the more formal control mode. This finding corroborates earlier suggestions that the way a network is managed is related to project innovativeness (Möller \& Svahn, 2006; Rindfleisch \& Moorman, 2001). If projects are highly uncertain, partners strive towards a 'strong commitment' to motivate actors to achieve joint goals, and refrain from explicit and formal control (Anderson, 1990). In contrast, less innovative projects are believed to benefit from a control-oriented management mode, as goals and separate tasks can be defined and their execution enforced. Network actors therefore adapt their management when the project moves into a next stage in the innovation process. This is in line with research suggesting that management modes should change over time (Anderson, 1990; Lowndes \& Skelcher, 1998; Provan \& Kenis, 2007). Taken together, we propose that network actors try to match the management mode to both network characteristics and the prevailing mental model of the network actors.

\section{Limitations and Directions for Further Research}

Our study provides an understanding of network management and may serve as a guide for additional empirical research into network management. However, as an exploratory study, it suffers from several limitations, which offer opportunities for further research. First, our results are based on a limited number of cases. While much of our data is collected in the context of critical incidents, suggesting that our findings reflect the central elements of network management, further research should use quantitative, large-sample methods to test our proposed taxonomy. Such research could also investigate when a particular mode is to be most expected. Our study suggests some factors that seem especially relevant (dependence, project innovativeness, prevailing mental model), but other factors may also be taken into account. 
Second, our study is purely descriptive and cannot provide insights in which management modes would work best in which situations as we did not include performance measures. We encourage future research along these lines. Qualitative Comparative Analysis may be helpful for such complex analyses.

Third, we studied relatively small, purposely built, innovation networks. We did not address large, more open networks that have emerged naturally. Such contingencies may influence the way networks are managed. Further research investigating larger, more open networks may increase the generalisability of our results. It would also be interesting to study innovation projects with short durations: in our dataset, even the cases with a predetermined ending were relatively long lasting (multiple years) and this may have resulted in findings with a stronger focus on relationship-building.

Fourth, we encourage future research to take a longitudinal perspective to investigate how networks may change network management over time. Our study suggests that network management may be strongly related to the prevailing mental model network actors hold, something that is not easily changed. Research along these lines may explain why many projects fail to make a successful transition from the growth phase to the maturity phase and how to overcome this problem.

Despite these limitations, we believe this study provides an important next step toward a better understanding of the complex concept of network management and we hope it serves as the basis for further endeavours in this direction.

\section{Acknowledgments}

This work was supported by a grant from TransForum (WP-082). 


\section{References}

Aarikka-Stenroos, L., Sandberg, B., \& Lehtimäki, T. (2014). Networks for the commercialization of innovations: a review of how divergent network actors contribute. Industrial Marketing Management, 43, 365-381.

Anderson, E. (1990). Two firms one frontier: on assessing joint venture performance. Sloan Management Review, 31, 19-30.

Anderson, J.C., Håkansson, H., \& Johanson, J. (1994). Dyadic business relationships within a business network context. Journal of Marketing, 58, 1-15.

Avadikyan, A., Llerena, P., Matt, M., Rozan, A., \& Wolff, S. (2001). Organizational rules, codification and knowledge creation in inter-organization cooperative agreements. Research Policy, 30, 1443-58.

Bailey, K.D. (1994). Typologies and taxonomies: an introduction to classification techniques. Thousand Oaks, CA: Sage.

Blomqvist, K., \& Levy, J. (2006). Collaboration capability: a focal concept in knowledge creation and collaborative innovation in networks. International Journal of Management Concepts and Philosophy, 2, 31-48.

Bridoux, F., \& Stoelhorst, J.W. (2014). Microfoundations for stakeholder theory: managing stakeholders with heterogeneous motives. Strategic Management Journal, 35, 107-125.

Capaldo, A. (2014). Network governance: a cross-level study of social mechanisms, knowledge benefits, and strategic outcomes in joint-design alliances. Industrial Marketing Management, 43, 685-703.

Das, T.K., \& Teng, B.-S. (2001). Trust, control, and risk in strategic alliances: an integrated framework. Organization Studies, 22, 251-83. 
Davis, J.S., \& Eisenhardt, K.M. (2011). Rotating leadership and collaborative innovation: recombination processes in symbiotic relationships. Administrative Science Quarterly, 56, 159201.

Dhanaraj, C., \& Parkhe, A. (2006). Orchestrating innovation networks. Academy of Management Review, 31, 659-69.

Dougherty, D., \& Dunne, D.D. (2011). Organizing ecologies of complex innovation. Organization Science, 22, 1214-23.

Dyer, J.H., \& Singh, H. (1998). The relational view: cooperative strategy and sources of interorganizational competitive advantage. Academy of Management Review, 23, 660-79.

Easton, G. (1992). Industrial networks: a review. In Axelson, B. \& Easton, G. (eds) Industrial networks: a new view of reality. London: Routledge. p. 3-27.

Flanagan, J. C. (1954). The critical incident technique. Psychological Bulletin, 51, 327-58.

Grandori, A. (1997). An organizational assessment of inter-firm coordination modes. Organization Studies, 18, 897-925.

Grandori, A., \& Soda, G. (1995). Inter-firm networks: antecedents, mechanisms and forms. Organization Studies, 16, 183-214.

Gulati, R. (1995). Does familiarity breed trust? The implications of repeated ties for contractual choice in alliances. Academy of Management Journal, 38, 85-112.

Gulati, R., \& Singh, H. (1998). The architecture of cooperation: managing coordination costs and appropriation concerns in strategic alliances. Administrative Science Quarterly, 43, 781-814.

Håkansson, H. (1987). Industrial technological development: a network approach. London: Croom Helm. 
Håkansson, H., Ford, D., Gadde, L-E., Snehota, I, \& Waluszewski, A. (2009). Business in networks. Chichester, UK: Wiley.

Håkansson, H., \& Snehota, I. (1989). No business is an island: the network concept of business strategy. Scandinavian Journal of Management, 5, 187-200.

Heikkinen, M.T., Mainela, T., Still, J., \& Tahtinen, J. (2007). Roles for managing in mobile service development nets. Industrial Marketing Management, 36, 909-925.

Holmlund, M., \& Törnroos, J.-^̊. (1997). What are relationships in business networks? Management Decision, 35, 304-309.

Järvensivu, T., \& Möller, K. (2009). Metatheory of network management: a contingency perspective. Industrial Marketing Management, 38, 654-61.

Jick, T.D. (1979). Mixing qualitative and quantitative methods: triangulation in action. Administrative Science Quarterly, 24, 602-11.

Jones, C., Hesterly, W.S., \& Borgatti, S.P. (1997). A general theory of network governance: exchange conditions and social mechanisms. Academy of Management Review, 22, 911-45.

Kenis, P., \& Provan, K. G. (2006). The control of public networks. International Public Management Journal, 9, 227-47.

Klein Woolthuis, R., Hillebrand, B., \& Nooteboom, B. (2005). Trust, contract and relationship development. Organization Studies, 26, 813-40.

Kumar, N., Scheer, L.K., \& Steenkamp, J.B.E.M. (1998). The effects of perceived interdependence on dealer attitudes. Journal of Marketing Research, 32, 348-56.

Larson, A. (1992). Network dyads in entrepreneurial settings: a study of the governance of exchange relationships. Administrative Science Quarterly, 37, 76-104. 
Lin, H.-M., Huang, H.-C., Lin, C.-P., \& Hsu, W.-C. (2012). How to manage strategic alliances in OEM-based industrial clusters: network embeddedness and formal governance mechanisms. Industrial Marketing Management, 41, 449-459.

Lowndes, V., \& Skelcher, C. (1998). The dynamics of multi-organizational partnerships: an analysis of changing modes of governance. Public Administration, 76, 313-33.

Luo, Y. (2002). Contract, cooperation, and performance in international joint ventures. Strategic Management Journal, 23, 903-19.

Malhotra, D., \& Murnighan, J.K. (2002). The effects of contracts on interpersonal trust. Administrative Science Quarterly, 47, 534-59.

Manser, K., Hillebrand, B., Driessen, P.H., Ziggers, G. W., \& Bloemer, J.M.M. (2015). Activity sets in multi-organizational ecologies: a project-level perspective on sustainable energy innovations. Technological Forecasting and Social Change, 90, 444-455.

McGregor, D. (1960). The human side of enterprise. New York NY: McGrawHill.

McGuire, M. (2002). Managing networks: propositions on what managers do and why they do it. Public Administration Review, 62, 599-609.

Miles, M.B., \& Huberman, M.A. (1994). Qualitative Data Analysis. Beverly Hills CA: Sage. Mõller, K.K., \& Halinen, A. (1999). Business relationships and networks: managerial challenge of network era. Industrial Marketing Management, 28, 413-427.

Möller, K., \& Svahn, S. (2003). Managing strategic nets. Marketing Theory, 3, 209-34.

Möller, K. \& Svahn, S. (2006). Role of knowledge in value creation in business nets. Journal of Management Studies, 43, 985-1007.

Ouchi, W.G. (1979). A conceptual framework for the design of organizational control mechanisms. Management Science, 25, 833-48. 
Osborn, R.N., \& Baughn, C.C. (1990). Forms of interorganizational governance for multinational alliances. Academy of Management Journal, 33, 503-19.

Park, S.H. (1996). Managing an interorganizational network: a framework of the institutional mechanism for network control. Organization Studies, 17, 795-824.

Podolny, J.M., \& Page, K.L. (1998). Network forms of organization. Annual Review Sociology, 24, 57-76.

Poppo, L., \& Zenger, T.R. (2002). Do formal contracts and relational governance function as substitutes or complements? Strategic Management Journal, 23, 707-25.

Powell, W.W. (1990). Neither market nor hierarchy: network forms of organization. Research in Organizational Behavior, 12, 295-336.

Prahalad, C.K., \& Bettis, R.A. (1986). The dominant logic: a new linkage between diversity and performance. Strategic Management Journal, 7, 485-501.

Provan, K.G. (1983). The federation as an interorganizational linkage network. Academy of Management Review, 8, 79-89.

Provan, K.G., \& Kenis, P. (2007). Modes of network governance: structure, management, and effectiveness. Journal of Public Administration Research and Theory, 18, 229-257.

Provan, K.G., \& Milward, H.B. (1995). A preliminary theory of interorganizational network effectiveness: a comparative study of four mental health systems. Administrative Science Quarterly, 40, 1-33.

Provan, K.G., \& Kenis, P. (2007). Modes of network governance: structure, management, and effectiveness. Journal of Public Administration Research and Theory, 18, 229-57.

Provan, K.G., Fish, A., \& Sydow, J. (2007). Interorganizational networks on the network level: a review of the empirical literature on whole networks. Journal of Management, 33, 479-516. 
Rampersad, G., Quester, P., \& Troshani, I. (2010). Managing innovation networks: exploratory evidence from ICT, biotechnology and nanotechnology networks. Industrial Marketing Management, 39, 793-805.

Rindfleisch, A., \& Moorman, C. (2001). The acquisition and utilization of information in new product alliances: a strength-of-ties perspective. Journal of Marketing, 65, 1-18.

Ring, P.S., \& van de Ven, A. (1994). Developmental processes of cooperative interorganizational relationships. Academy of Management Review, 19, 90-118.

Ritter, T. (1999). The networking company; antecedents for coping with relationships and networks effectively. Industrial Marketing Management, 28, 467-479.

Ritter, T., \& Gemünden, H.G. (2003). Network competence: its impact on innovation success and its antecedents. Journal of Business Research, 56, 745-755.

Ritter, T., Wilkinson I.F., \& Johnston, W.J. (2002). Measuring network competence: some international evidence. Journal of Business and Industrial Marketing, 17, 119-183.

Ritter, T., Wilkinson I.F., \& Johnston, W.J. (2004). Managing in complex business networks. Industrial Marketing Management, 33, 175-83.

Roy, J-P. (2012) IJV partner trustworthy behaviour: the role of host country governance and partner selection criteria. Journal of Management Studies, 49, 332-355.

Sager, K.L. (2008). An exploratory study of the relationship between theory X/Y assumptions and superior communicator style. Management Communication Quarterly, 22, 288-312.

Sahin, F. (2012). The mediating effect of leader-member exchange on the relationship between theory $\mathrm{X}$ and $\mathrm{Y}$ management styles and affective commitment: a multilevel analysis. Journal of Management and Organization, 18, 159-74. 
Teece, D.J. (1992). Competition, cooperation, and innovation: organizational arrangements for regimes of rapid technological progress. Journal of Economic Behavior and Organization, 18, 125.

Tenbrunsel, A.E., \& Messick, D.M. (1999). Sanctioning systems, decision frames, and cooperation. Administrative Science Quarterly, 44, 684-707.

Thorgren, S., Wincent, J., \& Örtqvist, D. (2009). Designing interorganizational networks for innovation: an empirical examination of network configuration, formation and governance. Journal of Engineering and Technology Management, 26, 148-66.

Truss, C., Gratton, L., Hope-Hailey, V., McGovern, P., \& Stiles, P. (1997). Soft and hard models of human resource management: a reappraisal. Journal of Management Studies, 34, 53-73.

Tsoukas, H. (1994). What is management? An outline of a metatheory. British Journal of Management, 5, 289-301.

Van Dyne, L., \& LePine, J.A. (1998). Helping and voice extra-role behaviors: evidence of construct and predictive validity. Academy of Management Journal, 41, 108-19.

Walter, A., Auer, M., \& Ritter, T. (2006). The impact of network capabilities and entrepreneurial orientation on university spin-off performance. Journal of Business Venturing, 21, 541-567.

Watson, T. (2006). Organizing and managing work: organizational, managerial and strategic behavior in theory and practice. New York, NY: Pearson.

Williamson, O.E. (1985). The economic institutions of capitalism. New York, NY: Free Press.

West, J., \& Bogers, M. (2014). Leveraging external sources of innovation: a review of research on open innovation. Journal of Product Innovation Management, 31, 814-831.

Wuyts, S., \& Geyskens, I. (2005). The formation of buyer-supplier relationships: detailed contract drafting and close partner selection. Journal of Marketing, 69, 103-17. 
Yin, R.K. (1994). Case study research - design and methods. Thousand Oaks, CA: Sage.

Zeng, S.X., Xie, X.M., \& Tam, C.M. (2010). Relationship between cooperation networks and innovation performance of SMEs. Technovation, 30, 181-194. 


\section{Appendix A: Case Descriptions}

\section{Bus case}

The Bus case project was initiated in 2008 and still operated at the time of data collection. It aims to develop an energy-efficient bus that eliminates friction in the power transfer. In a conventional traction arrangement, $50 \%$ of the energy used by a city bus is wasted by these friction-producing power transfers. The bus can cover four times as much distance with the same amount of fuel compared with a conventional diesel bus. The project aims to develop five city buses and test them in a Dutch city. Three main actors are responsible for the day-to-day project activities: the bus inventor, the concession holder, and a foundation that is the official project leader. Other parties involved in the project include the city in which the buses are tested and the Ministry of Infrastructure and Environment. Thus far the network has not been able to meet all project objectives.

\section{Food Chain case}

This project started in 2007 and lasted until 2010. It aimed to develop a supply chain for fresh, seasonal and sustainably produced vegetables and fruits from rural areas into cities. Unlike regular supply chains for vegetables and fruits, this new type of supply chain is very short and transparent, enabling consumers to build a direct relationship with the farmers who grow the products. This project was initiated by two foundations (which are no longer part of the network) that wanted to bring cities back in touch with rural areas. The main remaining actors are a governmental organization, the food chain organization, and two universities. The project has not met all its goals and after being in financial difficulties in 2010 , the food chain organization has been sold. 


\section{Breathing Window case}

The Breathing Window project started in 2007 and refers to a continuing collaboration between several entrepreneurs. The project aims to develop a sustainable alternative for heat recovery ventilation and air conditioning. It builds on previously tested knowledge, making the product relatively simple to produce. The cooperation mainly takes place between two technology-driven entrepreneurs and a network of investors. Another partner that was in charge of the product launch turned out to sell its own ventilation system, thus effectively blocking the market for the new product. The inventor then decided to take production and distribution in his own hands. Overall, the project is considered very successful from a technological and cooperation perspective.

\section{Greenhouse case}

This innovation project lasted from 2005 to 2008. It aimed to develop and stimulate the adoption of (semi-)closed greenhouses, i.e., greenhouses that use geothermal and/or solar energy and minimize the amount of energy waste. The network included growers who already used (semi)closed greenhouses or had plans to do so in the future, suppliers of greenhouses, several university researchers, and several governmental and non-governmental institutions. Every six weeks platform meetings were organized to give network actors the opportunity to share their experiences with the new greenhouse system, to exchange information on trends on greenhouses and related fields and on subsidies. . Network actors perceived the project as successful in terms of stimulating the development and adoption of (semi-)closed greenhouses, although the innovation itself, the (semi)closed greenhouse, did not meet high initial expectations. 


\section{Packaging case}

The network working on the packaging project was initiated in 2008 and still functioning at the time of data collection. The innovation involves packaging material that is $100 \%$ bio-degradable and compostable, as an environmentally friendly alternative to polystyrene and molded paper packaging materials. The new packaging material is made of natural fibres and uses natural binders. The material can be used as shock absorbing and filling material to package household appliances, furniture or food. The network consists of seven actors, but three of them (including the inventor and a packaging manufacturer) cooperate with each other on a day to day basis. The network thus far has reached its predefined goals and is on schedule.

\section{Printer case}

The Printer case lasted from 2009 to 2012 and focused on developing a system for heat recovery from printing presses, to heat and cool the printer's building. The network was comprised of a complementary network of a builder, architect, printer, and equipment installer. Two external project leaders were involved to coordinate the process: one in the field of subsidy and financing, and one on climate control and energy reduction. The project was delayed substantially by the lack of coordination between the architect and builder on the one hand, and the supplier and installer of the equipment on the other. Although no optimal solution was reached, the project was successful in the sense that the system worked, with few start-up problems. Because of the innovative character of the project, it was a light-house example for smart energy reduction in the printing industry. 


\section{C2C Building case}

The $\mathrm{C} 2 \mathrm{C}$ case involves a continuing collaboration in a network of complementary partners, from 2003 onwards. It was built on successful earlier project collaboration and was formalized in a contractual structure. The network comprises of a builder, project developer and installer who aim to create innovative new office buildings based on cradle to cradle principles. This involves the development of new products and concepts, and the integration into new buildings. The collaboration is successful and business flourishes, even during the real estate crisis years of 2008-2012.

\section{Electric Car case}

This project started in 2007 and lasted until 2010. It involved the development of an electrically powered, lightweight, plastic car. The project was initiated by one organization and undertaken together with several suppliers, technicians, and commercial partners. Technically, the project was a success: in 2008, the first five prototypes were manufactured and introduced at the Paris Motor Show. It attracted a lot of attention as one of the first electrically powered car that was ready for commercial production. However, financial difficulties led to the sale of the innovation to a Chinese investor.

\section{Hen Housing case}

This project lasted from 2007 to 2010. The innovation involved a hen housing system that integrates animal welfare standards comparable to free range or organic (open air) laying hen husbandry (e.g., natural shelter) with the advantages of closed hen housing systems that produce cage or barn eggs (e.g., protection against aviary airborne diseases). The main players in this 
network were the organization responsible for building the housing system, a governmental organization, a university, the farmer on whose grounds the system has been built, and the city in which the project took place. This project has been a great success, exceeding expectations.

\section{Bulb Drying case}

This network collaboration took place from 2005 to 2008. The network consisted of a flower bulb grower, installer, equipment manufacturer, and an external advisor. The project started with a joint idea of how bulbs could be dried more sustainably. This resulted in a shared project to develop a new method of drying flower bulbs with a low temperature heat recovery system based on renewable sources. The collaboration was successful and led to a well-functioning system, but after the project the collaboration stalled as the installer was unwilling to work together on the maintenance and adjustments that the system needed to function optimally.

\section{Organic Rankine case}

The Organic Rankine case lasted from 2001 to 2012. The project was a demonstration project of how fermentation of bio-degradable materials can produce energy, i.e. the organic rankine cycle technology. Whereas this technology was proven in a lab setting, it had not yet been developed into a commercial product. The network consisted of an inventor, an equipment developer, two technical universities, and investors. During the project some partners were replaced by others. While the project faced several problems (including an exploding first prototype), the end result was considered a success, resulting in a machine that scores very high on efficiency and $98 \%$ availability (no errors). 


\section{Appendix B: Abridged topic list for the interviews}

\section{Background questions about the product, the network, and the actors}

- Could you describe the product? (in terms of functionality, newness, customer advantages, complexity etc.)

- What was the origin and goal of the project? Do you consider the project to be a success?

- Who participated in the project? What was their role? Did they have similar goals? Did they depend on each other?

\section{Critical incident technique}

- Do you remember a moment that stood out as a particular positive/negative moment? when? what happened? who was involved? how dealt with? result?

\section{Open questions}

- How do the actors know what they have to do? How are activities synchronized?

- How does the network ensure network participants show the desired behaviour?

- How are project participants managed? In general, who was managing the project?

\section{Questions on network management activities}

- To what extent was everyone allowed to participate? What selection criteria were used?

- To what extent did the network rely on shared goals, norms and values for coordination?

To what degree did participants correct each other?

- To what extent and how did project participants communicate with each other?

- To what extent did the network use pre-defined goals, protocols, contracts, plans?

- To what extent were the activities of participants observed and evaluated?

- To what extent are incentives and rewards used to manage the network? 
Table 1: Network Descriptions

\begin{tabular}{|c|c|c|c|c|c|c|c|c|c|c|c|}
\hline & Bus & $\begin{array}{l}\text { Food } \\
\text { chain }\end{array}$ & $\begin{array}{l}\text { Breathing } \\
\text { window }\end{array}$ & Greenhouse & Packaging & Printer & $\begin{array}{l}\text { C2C } \\
\text { Building }\end{array}$ & $\begin{array}{l}\text { Electric } \\
\text { car }\end{array}$ & $\begin{array}{l}\text { Hen } \\
\text { housing }\end{array}$ & $\begin{array}{l}\text { Bulb } \\
\text { drying } \\
\text { system }\end{array}$ & $\begin{array}{l}\text { Organic } \\
\text { rankine }\end{array}$ \\
\hline $\begin{array}{l}\text { Predetermined } \\
\text { deadline }\end{array}$ & Yes & Yes & No & Yes & No & Yes & No & No & Yes & Yes & Yes \\
\hline $\begin{array}{l}\text { Number of } \\
\text { participants }\end{array}$ & 9 & 6 & 4 & 29 & 7 & 4 & 3 & 5 & 15 & 4 & 3 \\
\hline Project success & Low & Low & $\begin{array}{l}\text { Low- } \\
\text { Medium }\end{array}$ & Medium & High & Low & High & Medium & High & Medium & High \\
\hline $\begin{array}{l}\text { Contract } \\
\text { completeness }\end{array}$ & Medium & Low & Medium & Low & High & High & High & High & High & Medium & Low \\
\hline $\begin{array}{l}\text { Project } \\
\text { innovativeness }\end{array}$ & High & Low & High & Medium & Low & Medium & Medium & High & Medium & Medium & High \\
\hline Trust & Medium & Low & Medium & Medium & Medium & Medium & High & High & High & Medium & High \\
\hline Dependence* & A & A & A & $\mathrm{S}$ & $\mathrm{S}$ & $S$ & S & $S$ & $\mathrm{~S}$ & $\mathrm{~S}$ & $\mathrm{~S}$ \\
\hline $\begin{array}{l}\text { Selection on } \\
\text { capability }\end{array}$ & Medium & Medium & Medium & High & High & High & High & Medium & High & Medium & High \\
\hline $\begin{array}{l}\text { Selection on } \\
\text { motivation }\end{array}$ & Low & Low & Medium & Medium & Medium & Low & Low & High & High & High & High \\
\hline
\end{tabular}

* A=asymmetric, $\mathrm{S}=$ symmetric 
Table 2: Description of Case Data

\begin{tabular}{|c|c|c|c|}
\hline Project & $\begin{array}{l}\text { Number of } \\
\text { interviews }\end{array}$ & $\begin{array}{l}\text { Duration interviews } \\
\text { (in minutes) }\end{array}$ & Documents (total pages) $* * *$ \\
\hline Bus & 3 & 232 & $\begin{array}{l}\text { Project plan, overview of planning, website of } \\
\text { initiating company, contract ( } 52 \text { pages) }\end{array}$ \\
\hline Food chain & 4 & $322 *$ & $\begin{array}{l}\text { Project plan, monitoring reports, cooperation } \\
\text { agreements, project reports ( } 231 \text { pages) }\end{array}$ \\
\hline $\begin{array}{l}\text { Breathing } \\
\text { window }\end{array}$ & 6 & $370 * *$ & $\begin{array}{l}\text { Project plan, reports, budget, article, product } \\
\text { leaflets ( } 72 \text { pages) }\end{array}$ \\
\hline Greenhouse & 5 & 383 & $\begin{array}{l}\text { Project plan, monitoring reports, project reports, } \\
\text { scientific articles ( } 303 \text { pages })\end{array}$ \\
\hline Packaging & 3 & 204 & $\begin{array}{l}\text { Planning, website initiating company, other } \\
\text { information found on internet, press releases, } \\
\text { contracts ( } 20 \text { pages) }\end{array}$ \\
\hline Printer & 4 & 312 & $\begin{array}{l}\text { Project plan, reports, budget, websites, } \\
\text { newspaper articles ( } 18 \text { pages) }\end{array}$ \\
\hline $\mathrm{C} 2 \mathrm{C}$ building & 6 & 550 & $\begin{array}{l}\text { Project plan, contract, company and project } \\
\text { websites, project documentation, research } \\
\text { reports ( } 145 \text { pages) }\end{array}$ \\
\hline Electric car & 2 & 182 & $\begin{array}{l}\text { Press releases, website of initiating company, } \\
\text { other information found on internet ( } 20 \text { pages) }\end{array}$ \\
\hline Hen housing & 6 & 388 & $\begin{array}{l}\text { Project plan, monitoring reports, articles, project } \\
\text { reports ( } 98 \text { pages) }\end{array}$ \\
\hline $\begin{array}{l}\text { Bulb drying } \\
\text { system }\end{array}$ & 4 & 191 & $\begin{array}{l}\text { Project plan, monitoring reports, budget, } \\
\text { company websites, research report (121 pages) }\end{array}$ \\
\hline Organic rankine & 4 & 208 & $\begin{array}{l}\text { Presentation slides, company website, project } \\
\text { plans, reports, budget ( } 86 \text { pages) }\end{array}$ \\
\hline Total & 47 & $3342(=56$ hours $)$ & 1226 pages \\
\hline
\end{tabular}


Table 3: Overview of Network Management Activities and Modes

\begin{tabular}{|c|c|c|c|c|c|c|c|c|c|c|c|}
\hline \multirow[t]{2}{*}{ Activities } & \multicolumn{3}{|c|}{ Basically coordinated mode } & \multicolumn{4}{|c|}{ Control-oriented mode } & \multicolumn{4}{|c|}{ Reward-oriented mode } \\
\hline & Bus & Food chain & $\begin{array}{l}\text { Breathing } \\
\text { window }\end{array}$ & Greenhouse & Packaging & Printer & $\begin{array}{l}\mathrm{C} 2 \mathrm{C} \\
\text { building }\end{array}$ & $\begin{array}{l}\text { Electric } \\
\text { car }\end{array}$ & $\begin{array}{l}\text { Hen } \\
\text { housing }\end{array}$ & $\begin{array}{l}\text { Bulb drying } \\
\text { system }\end{array}$ & $\begin{array}{l}\text { Organic } \\
\text { rankine }\end{array}$ \\
\hline $\begin{array}{l}\text { Communicating } \\
\text { for coordination }\end{array}$ & High & Medium & High & High & High & High & High & High & High & High & High \\
\hline Planning & High & Medium & Medium & Medium & High & High & High & High & High & High & High \\
\hline Monitoring & High & High & High & High & High & High & High & High & High & High & High \\
\hline $\begin{array}{l}\text { Sanctioning } \\
\text { informal }\end{array}$ & Absent & Medium & Absent & High & High & Absent & Absent & Low & Absent & Absent & Low \\
\hline $\begin{array}{l}\text { Sanctioning } \\
\text { formal }\end{array}$ & Absent & Absent & Absent & Absent & High & High & Absent & Absent & Absent & Absent & Absent \\
\hline $\begin{array}{l}\text { Using ex ante } \\
\text { social control }\end{array}$ & Absent & Absent & Medium & High & High & High & High & Low & Absent & Medium & Medium \\
\hline $\begin{array}{l}\text { Using ex post } \\
\text { social control }\end{array}$ & Absent & Low & Absent & High & High & High & High & Medium & Absent & Low & Low \\
\hline $\begin{array}{l}\text { Communicating } \\
\text { for stimulation }\end{array}$ & Low & $\begin{array}{l}\text { Low- } \\
\text { Medium }\end{array}$ & Medium & Medium & Low & Low & Low & High & High & High & High \\
\hline $\begin{array}{l}\text { Rewarding } \\
\text { formal }\end{array}$ & Absent & Absent & Absent & Absent & Absent & Absent & Absent & High & High & High & Medium \\
\hline $\begin{array}{l}\text { Rewarding } \\
\text { informal }\end{array}$ & Absent & Absent & Medium & Absent & Absent & Absent & Low & High & High & Medium & High \\
\hline $\begin{array}{l}\text { Encouraging } \\
\text { solidarity } \\
\text { atmosphere }\end{array}$ & Absent & Absent & Medium & Absent & Absent & Absent & Low & High & High & High & High \\
\hline
\end{tabular}

